\title{
64. Acute Effects of Carbon Monoxide on Cerebral pH and Energy Metabolism Studied by Non-Invasive Phosphorus-31 NMR
}

\author{
By Hisateru Mitsuda, M. J. A., Yasuyoshi Azuma, Yasuaki Kawasaki, \\ Kunpei KaWATA, and Fumio KaWAI \\ The Foundation of Interdisciplinary Research Institute of Environmental Sciences, \\ Nishi-iru, Shichihon-matsu, Itsutsuji-dori, Kamigyo-ku, Kyoto 602
}

(Communicated Oct. 12, 1988)

Introduction. Carbon monoxide ( $\mathrm{CO}$ ), a major atmospheric pollutants, is a leading cause of poisoning or intoxication, and there are many studies on its effects on humans. ${ }^{1)-3}$ ) The extent of damage induced by carbon monoxide depends on the blood carboxyhemoglobin ( $\mathrm{COHb}$ ) level and the duration of exposure. The increase in the $\mathrm{COHb}$ level leads to lowered oxygen delivery to the tissues. The brain and heart muscles are very sensitive to this hypoxic condition, and are easily damaged. Metabolic acidosis is also significant manifestation in CO poisoning. A biochemical study revealed that the intracellular $\mathrm{pH}$ of rat brain dropped to 6.46 by inhalation of CO. ${ }^{4}$ However, the time course of change in intracellular $\mathrm{pH}$ in brain during $\mathrm{CO}$ inhalation or exposure is still unknown, because the intracellular $\mathrm{pH}$ is difficult to measure non-invasively, especially in brain, with conventional biochemical techniques.

Phosphorus nuclear magnetic resonance spectroscopy is a non-invasive method for determining intracellular changes in high energy phosphates, ${ }^{5}$ and it also gives us information about the change in $\mathrm{pH}^{6)-8}$ )

We investigated the change in intracellular $\mathrm{pH}$ of rat brain during $\mathrm{CO}$ inhalation, as well as changes in high energy phosphates, using in vivo ${ }^{31} \mathrm{P}$ NMR spectroscopy.

Materials and methods. Male Sprague-Dawley rats, each weighing about $170 \mathrm{~g}(169 \pm 3 \mathrm{~g})$, were anesthetized with pentobarbital sodium (50 mg/kg, i.p.) and intubated endotracheally. They were mechanically ventilated with a UgoBasile type 7025 ventilator after administration of pancuronium bromide $(0.5$ $\mathrm{mg} / \mathrm{kg}$, i.m.). To control the respiration of rat placed in the super conducting magnet, unusually long air tubes $(1.6 \mathrm{~m})$ were used. In the preliminary tests, animals were kept in the neighborhood of normoxic $\left(\mathrm{PaO}_{2} 101.5 \pm 2.9 \mathrm{mmHg}\right.$, $\mathrm{n}=4)$ and normocarbic $\left(\mathrm{PaCO}_{2} 40.3 \pm 1.9 \mathrm{mmHg}, \mathrm{n}=4\right)$ condition while ventilated with a tidal volume of $2 \mathrm{ml}$, a minute volume of $200 \mathrm{ml}$, using $1.6 \mathrm{~m}$ long tubes.

NMR measurements were made with a JNM GSX-270 spectrometer system (JEOL, Japan). The surface coil (11 $\mathrm{mm}$ in diameter, five-turn) for NMR detection (Fig. 1(A)) was placed against the scalp of the animal (Fig. 1(B)). The spectra were obtained at an operating frequency of $109.14 \mathrm{MHz}$ for phosphorus. Radiofrequency pulses of $20 \mu \mathrm{sec}$ duration were delivered every $1.5 \mathrm{sec}$ for NMR acquisition. It took 5 min to accumulate 200 scans for each measurement. Following collection of control data, inhalation of $5000 \mathrm{ppm} \mathrm{CO}$ (in air) was started. During the $40 \mathrm{~min}$ of inhalation, spectra were obtained every $10 \mathrm{~min}$. Data were accumulated during the last $5 \mathrm{~min}$ of each $10 \mathrm{~min}$. After the $\mathrm{CO}$ 
A

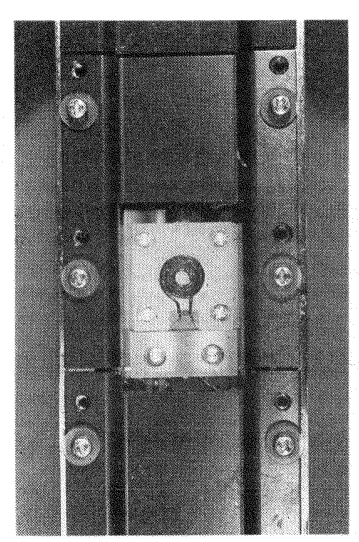

B

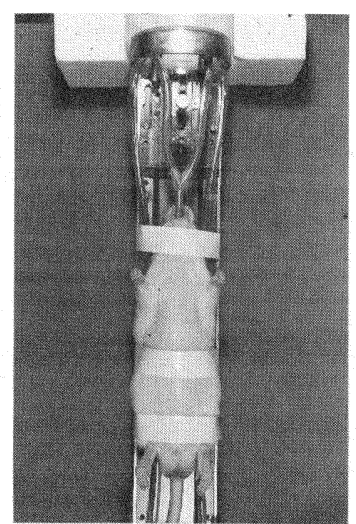

Fig. 1. A: The surface coil for NMR detection (five-turn, $11 \mathrm{~mm}$ in diameter) used in this study. B: Experimental animal fixed on the probe. The animal's head is placed right above the surface coil.

Table I. Changes in $\mathrm{Pi} / \mathrm{PCr}$ and intracellular $\mathrm{pH}$ of rat brain during and after CO $(5000 \mathrm{ppm})$ inhalation $(\mathrm{n}=7)$

\begin{tabular}{cccc}
\hline Time $(\min )^{*}$ & Inhaled gas & Pi/PCr & Intracellular $\mathrm{pH}$ \\
\hline 0 & Air & $0.56 \pm 0.05$ & $7.22 \pm 0.16$ \\
\hline 10 & $5000 \mathrm{ppm} \mathrm{CO}$ in air & $0.69 \pm 0.10$ & $7.19 \pm 0.02$ \\
20 & & $0.91 \pm 0.19$ & $6.93 \pm 0.16$ \\
30 & & $1.20 \pm 0.30$ & $6.59 \pm 0.08$ \\
40 & & $1.13 \pm 0.28$ & $6.61 \pm 0.23$ \\
50 & Air & $0.63 \pm 0.09$ & $6.69 \pm 0.19$ \\
60 & & $0.59 \pm 0.04$ & $6.91 \pm 0.27$ \\
70 & & $0.61 \pm 0.08$ & $7.13 \pm 0.13$ \\
\hline
\end{tabular}

Values are means \pm S. D. * Time at the moment that the data accumulation was finished. Time 0 means the point when control data accumulation ended.

inhalation, the data for recovery period were also obtained in the same way for $30 \mathrm{~min}$.

The intracellular $\mathrm{pH}\left(\mathrm{pH}_{\mathrm{i}}\right)$ was determined from the chemical shift of inorganic phosphate peak relative to phosphocreatine peak according to the following equation. ${ }^{9)} \mathrm{pH}_{1}=6.77-\log _{10}[2.51 /(\delta-3.22)-1.0]$, where $\delta$ is the chemical shift of inorganic phosphate $(\mathrm{ppm})$. The ratio of signal intensities of inorganic phosphate and phosphocreatine $(\mathrm{Pi} / \mathrm{PCr})$ was also obtained for each spectrum.

Results and discussion. Seven of all ten animals tested survived throughout the experiment. One died in the course of $\mathrm{CO}$ inhalation, the other two after inhalation. Fig. 2(A-H) shows a typical sequential change in the ${ }^{31} \mathrm{P}$ in vivo NMR spectra of brain obtained non-invasively from one of the surviving animal at each stage of the experiment. Fig. 2(I) shows a typical spectrum from dead animal. Changes in $\mathrm{Pi} / \mathrm{PCr}$ ratio and intracellular $\mathrm{pH}$ of brain for seven survivors during and after inhalation of $\mathrm{CO}$ are shown in Table I. CO inhalation gradually increased the $\mathrm{Pi} / \mathrm{PCr}$, and the ratio was almost normalized by ventilation with air after CO loading (Fig. 2(A-H), Table I). The intracellular pH 

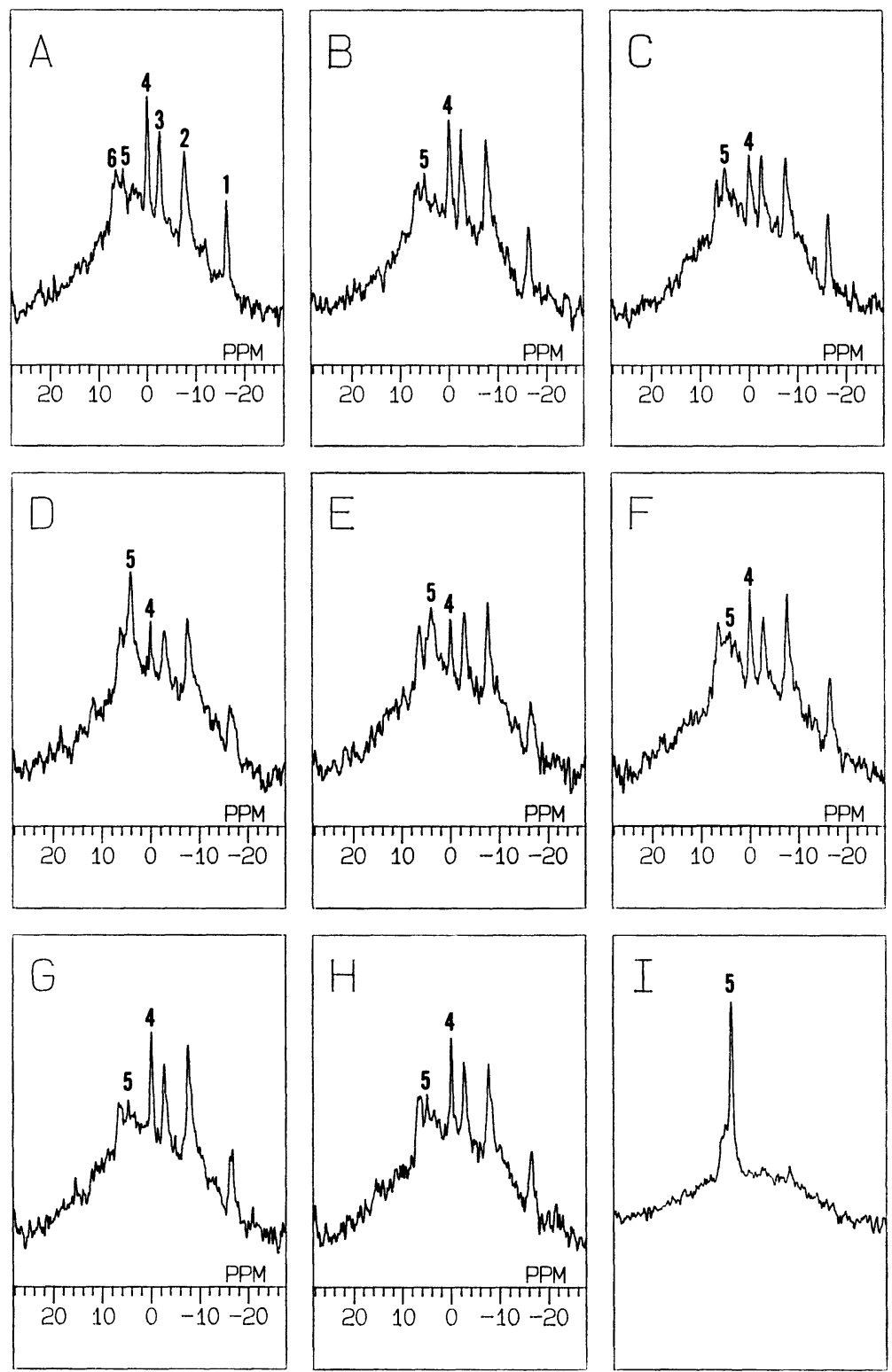

Fig. 2. The sequential change in ${ }^{31} \mathrm{P}$ in vivo $\mathrm{NMR}$ spectra of brain obtained from one animal during and after $\mathrm{CO}$ inhalation is shown in $\mathrm{A}-\mathrm{H}$ ( $\mathrm{A}$, control; $\mathrm{B}$, 10 min inhalation; C, 20 min inhalation; D, 30 min inhalation; $\mathrm{E}, 40 \mathrm{~min}$ inhalation; F, $10 \mathrm{~min}$ after inhalation; G, $20 \mathrm{~min}$ after inhalation; H, $30 \mathrm{~min}$ after inhalation). The spectrum shown in $I$ is from another animal that died during CO inhalation. The assignment of peaks is: $1, \operatorname{ATP}(\beta) ; 2, \operatorname{ATP}(\alpha)+\operatorname{ADP}(\alpha)$; 3, $\operatorname{ATP}(\gamma)+\operatorname{ADP}(\beta) ; 4$, phosphocreatine; 5, inorganic phosphate; 6, sugar phosphate. 
significantly dropped from $7.22 \pm 0.16$ (control) to $6.59 \pm 0.08$ (30 min CO inhalation), and returned to $7.13 \pm 0.13$ (30 min post-inhalation). The $\mathrm{pH}$ value 7.22 obtained in our control is in agreement with that reported by Litt et al.8) Interestingly, cerebral $\mathrm{pH}$ declined to 6.59 by $\mathrm{CO}$ inhalation, but it recovered to 7.13 within $30 \mathrm{~min}$. This rapid recovery may be related to the lack of accumulation of $\mathrm{CO}$ in the tissues as Sokal et al. ${ }^{10)}$ reported. Although accurate evaluation of the cerebral $\mathrm{pH}$ in dead animals is difficult because of the absence of the phosphocreatine peak in the NMR spectrum, the intracellular $\mathrm{pH}$ of three animals that died during or after the $\mathrm{CO}$ inhalation in this study seems to be below 6.5, and this value is compatible with the result of a biochemical study with DMO (5,5-dimethyl-2,4-oxazolidinedione) method reported by Gonmori.4)

Delivoria-Papadopoulos et al.11) reported changes in cerebral energy metabolism during $\mathrm{CO}$ inhalation. However, we are the first to report the sequential change in intracellular $\mathrm{pH}$ of brain during and after $\mathrm{CO}$ inhalation.

Further studies are needed to determine the relationship between the change in intracellular $\mathrm{pH}$ of brain and blood $\mathrm{COHb}$ levels.

\section{References}

1) Norman, J. N. et al. (1967) : Prog. Brain Res., 24, 101-122.

2) Goldsmith, J. R. et al. (1968) : Science, 162, 1352-1359.

3) Dolan, M. C. (1985): Can. Med. Assoc. J., 133, 392-399.

4) Gonmori, K. (1982): Akita J. Med., 9, 143-149.

5) Ackerman, J. J. H. et al. (1980): Nature, 283, 167-170.

6) Prichard, J. W. et al. (1983) : Proc. Natl. Acad. Sci. USA, 80, 2748-2751.

7) Naruse, S. et al. (1983) : Jpn. J. Physiol., 33, 19-28.

8) Litt, L. et al. (1985): J. Cereb. Blood Flow Metabol., 5, 537-544.

9) Seo, Y. et al. (1983) : J. Biochem., 94, 729-734.

10) Sokal, J. A. et al. (1984) : Arch. Toxicol., 56, 106-108.

11) Delivoria-Papadopoulos, M. et al. (1985): Fed. Proc., 44, 1010. 